\title{
Immunological Characterization of an Exopolysaccharide from the Staphylococcus aureus Strain Smith Diffuse
}

\author{
By TIMOThY E. WEST, ${ }^{1 * \dagger}$ B. A. LEWIS ${ }^{2}$ AND MICHAEL A. APICELLA ${ }^{1}$ \\ ${ }^{1}$ Division of Infectious Diseases, State University of New York at Buffalo, \\ Buffalo, New York 14215, USA \\ ${ }^{2}$ Division of Nutritional Sciences, Cornell University, Ithaca, New York 14853, USA
}

(Received 9 June 1986; revised 24 September 1986)

Exopolysaccharides (EXPs) of Staphylococcus aureus are associated with virulence in animal models. An EXP from the $S$. aureus strain Smith diffuse was previously detected in $64.3 \%$ of $S$. aureus clinical isolates. EXP was isolated from culture supernatants of this strain after DNAase, RNAase, phosphodiesterase I and lysostaphin treatment, and was further purified by cationexchange and molecular-sieve chromatography. Isoelectric focusing revealed a pI of 3.6 for the EXP while the pI of teichoic acid was $<2 \cdot 7$. Crossed immunoelectrophoresis with homologous Smith diffuse antisera indicated that the EXP contained two immunological components. A major precipitin line persisted after the antisera had been absorbed with the non-EXPproducing variant strain, Smith compact, while the second component was removed. Tandem immunoelectrophoresis also demonstrated that the EXP was distinct from teichoic acid. The EXP contained 2-amino-2-deoxyglucuronic acid, glucose, mannose and galactose. No fatty acids or nucleic acids were present and total protein content was $<2 \%$. Teichoic acid could not be demonstrated in the EXP, thus further substantiating the immunological studies. S. aureus EXP isolated by the present method can be used for further serological and virulence studies.

\section{INTRODUCTION}

The Staphylococcus aureus Smith diffuse strain was isolated from a patient with osteomyelitis in 1930 and was not described until 1956 (Smith \& Dubos, 1956). The strain attracted laboratory attention because of its unique capacity for causing a lethal peritonitis in mice (Hunt \& Moses, 1958). Koenig (1962) later isolated an avirulent variant (Smith compact strain) and demonstrated that the virulence of the Smith diffuse strain was related to the presence of an exopolysaccharide (EXP) that the variant, Smith compact, lacked.

We previously found that $64.3 \%$ of clinical $S$. aureus strains produced an EXP antigenically identical to the $S$. aureus Smith diffuse strain (West et al., 1985). Because of the common occurrence of the Smith diffuse EXP, we have now developed a method for its isolation free of teichoic acid. Immunological characterization of this preparation has been performed with crossed immunoelectrophoresis, tandem immunoelectrophoresis and isoelectric focusing. Preliminary biochemical analysis has indicated the absence of significant quantities of teichoic acid or peptidoglycan and established the major polysaccharide constituents. This new method for isolating a common $S$. aureus EXP should prove useful in further serological investigations of $S$. aureus infections.

† Present address: Medical Associates PA, Medical Arts Building, 65 Gadsden Street, Charleston, South Carolina 29401, USA.

Abbreviation: EXP, exopolysaccharide. 


\section{METHODS}

Materials. Culture media and additives were obtained from Difco, and DNAase (type I), RNAase (type I-AS), phosphodiesterase I and lysostaphin from Sigma. Other equipment and reagents were obtained from the indicated sources or were of reagent or higher grade.

Type strain and production of antisera. The $S$. aureus Smith diffuse strain and the nonencapsulated variant Smith compact strain were obtained from M. Ann Melly, Vanderbilt University, Nashville, Tenn., USA. Antiserum to the Smith diffuse strain was produced in rabbits (Oeding, 1957). Absorbed antisera were prepared by treating antisera to the Smith diffuse strain with each of the variant Smith strains.

Immunological analysis of bacterial antigens. Analysis was done in gels containing $1 \%(\mathrm{w} / \mathrm{v})$ agarose (Litex type LSL, Accurate Scientific Co., Westbury, NY) and 4\% (w/v) dextran T-70 (Pharmacia) in 0.025 $\mathrm{M}$-barbital/borate buffer (pH 8.6). Counter-immunoelectrophoresis was done in gels containing $3 \mathrm{~mm}$ diameter wells $5 \mathrm{~mm}$ apart, at a constant current of $15 \mathrm{~mA}$ per slide for $60 \mathrm{~min}$. The first dimension of crossed immunoelectrophoresis used a portion of the slide $(75 \times 15 \mathrm{~mm})$ with migration from cathode to anode at a constant voltage of $120 \mathrm{~V}$ for $2 \mathrm{~h}$. For the second phase, a constant voltage of $100 \mathrm{~V}$ was applied for $4 \mathrm{~h}$ and the remainder of the slide $(75 \times 35 \mathrm{~mm})$ filled with gel containing $19 \mu \mathrm{l}$ antiserum $\mathrm{cm}^{-1}$. Tandem immunoelectrophoresis was also used for simultaneous comparison of two antigen preparations.

Isoelectric focusing. The isoelectric point was determined by a preparative technique in Bio-lyte (Bio-Rad) with the appropriate Pharmalyte (Pharmacia) added to a final concentration of $2 \%$ (Righetti \& Drysdale, 1979). Antigen samples were applied to the middle of the gel and electrofocused at a constant power of $8-10 \mathrm{~W}$. The gel bed was then divided into 24 sections. The location of the antigens was determined by gel-immunodiffusion of the eluates from each section against the desired antisera.

Preparation of peptidoglycan and teichoic acid. Peptidoglycan was prepared from the $S$. aureus Smith compact strain as described by Peterson et al. (1978) and Verbrugh et al. (1981). The bacteria were cultured in broth containing $1.0 \%(\mathrm{w} / \mathrm{v})$ tryptose, $0.3 \%$ beef extract and $0.5 \% \mathrm{NaCl}$ for $18 \mathrm{~h}$ at $37{ }^{\circ} \mathrm{C}$ on a rotary shaker and harvested by continuous-flow centrifugation. Crude cell walls were obtained by vortexing the bacterial pellet with glass beads $\left(0 \cdot 10-0.15 \mathrm{~mm}\right.$ diam.) with buffer $\left(0.01 \mathrm{M}-\mathrm{K}_{2} \mathrm{HPO}_{4} / \mathrm{KH}_{2} \mathrm{PO}_{4}, 1.0 \mathrm{M}-\mathrm{NaCl}, \mathrm{pH} 7.4\right)$ for $15 \mathrm{~min}$ in the 'Bead-Beater' (Biospec Products, Bartlesville, OK, USA). Unbroken organisms and glass beads were removed by filtration through a sintered glass funnel. The crude cell walls were then pelleted by centrifugation at $25000 \mathrm{~g}$ for $20 \mathrm{~min}$. After resuspension of the pellet, the crude cell walls were successively treated by suspension in $2 \%(\mathrm{w} / \mathrm{v})$ sodium dodecyl sulphate with stirring for $16 \mathrm{~h}$; digestion with DNAase, RNAase A, and pronase (Calbiochem) in $0.05 \mathrm{M}$-Tris $/ \mathrm{HCl}, 0.005 \mathrm{M}-\mathrm{MgCl}_{2}, 0.005 \%$ thimerosal, $\mathrm{pH} \mathrm{7.4;} \mathrm{stirring} \mathrm{with} 40 \%$ phenol for $30 \mathrm{~min}$ at $25^{\circ} \mathrm{C}$; centrifuging and extensive washing with distilled water; and finally lyophilization.

Teichoic acid was removed from the purified cell walls by extraction with $100 \mathrm{ml} 10 \%(\mathrm{w} / \mathrm{v})$ TCA for $72 \mathrm{~h}$ at $4{ }^{\circ} \mathrm{C}$. The cell walls and debris were removed by centrifugation and the teichoic acid was collected from the supernatant by membrane filtration (Type PM-10, Amicon). This teichoic acid was further treated with lysostaphin, dissolved in $1.0 \mathrm{M}-\mathrm{NaCl}, 0.005 \%$ thimerosal, and applied to a Sephadex G-150 column (Pharmacia) to remove residual cell wall.

Peptidoglycan was prepared from the previously treated cell walls by further extraction of any residual teichoic acid with $20 \%(\mathrm{w} / \mathrm{v}) \mathrm{TCA}$ at $60^{\circ} \mathrm{C}$ for $90 \mathrm{~min}$. The peptidoglycan was then washed four times with distilled water and lyophilized.

Preparation of EXP. The $S$. aureus Smith diffuse strain was cultured overnight in 41 Columbia broth supplemented with $1 \%(\mathrm{w} / \mathrm{v})$ yeast extract at $37^{\circ} \mathrm{C}$ on a rotary shaker. The broth cultures were then formalinized $\left(0.5 \%\right.$ fluid concn) and heated to $60^{\circ} \mathrm{C}$ for $20 \mathrm{~min}$ while on the rotary shaker. The $\mathrm{pH}$ of the cultures was adjusted to 7.4 and they were shaken overnight with DNAase, RNAase, phosphodiesterase, lysostaphin, and pronase at $37^{\circ} \mathrm{C}$. The next morning the $\mathrm{pH}$ of the treated cultures was lowered to 2.60 and the unbroken bacteria were removed by centrifugation at $10000 \mathrm{~g}$ for $30 \mathrm{~min}$. The supernatant was dialysed against buffer $\mathrm{A}(\mathrm{pH} 2.60$ ), which contained: glycine, $5 \cdot 1 \mathrm{~g} \mathrm{l}^{-1} ; \mathrm{NaCl}, 4 \cdot 0 \mathrm{~g} \mathrm{l}^{-1} ; 0.03 \mathrm{M}-\mathrm{HCl}$, and applied to a SP-Sephadex cation-exchange column (type C-50, Pharmacia), then equilibrated with buffer B (pH 2.60), which contained: glycine, $20 \cdot 3 \mathrm{~g} \mathrm{l}^{-1} ; \mathrm{NaCl}$, $15.8 \mathrm{~g} \mathrm{l}^{-1} ; 0.1 \mathrm{M}-\mathrm{HCl}$. The EXP was eluted with buffer $\mathrm{C}(\mathrm{pH} 3.60)$, which contained: glycine, $70.7 \mathrm{~g} \mathrm{l}^{-1} ; \mathrm{NaCl}^{\text {, }}$ $58.3 \mathrm{~g} \mathrm{l}^{-1} ; 0.06 \mathrm{M}-\mathrm{HCl}$. This eluate was dialysed against $1.0 \mathrm{M}-\mathrm{NaCl}, 0.02 \% \mathrm{NaN}_{3}, \mathrm{pH} 7.4$, and concentrated by membrane filtration (type PM-30).

For molecular-sieve chromatography, the dialysed and concentrated eluate was then applied to a Sepharose 6B column (Pharmacia) and eluted with $1.0 \mathrm{M}-\mathrm{NaCl}, 0.02 \% \mathrm{NaN}_{3}, \mathrm{pH} 7 \cdot 4$. The immunologically active fractions were dialysed against distilled water, concentrated by membrane filtration, and lyophilized.

Chemical analysis. Antigens for chemical analysis were weighed and hydrolysed, in vacuo, with $3 \mathrm{M}-\mathrm{HCl}$ for $16 \mathrm{~h}$ at $100^{\circ} \mathrm{C}$. Neutral sugars were also analysed after hydrolysis either in $2 \mathrm{M}$-trifluoroacetic acid at $120^{\circ} \mathrm{C}$ for $2 \mathrm{~h}$ or in $4 \mathrm{M}-\mathrm{HCl}$ at $120^{\circ} \mathrm{C}$ for $3 \mathrm{~h}$. Acid was removed under vacuum during centrifugation at $7000 \mathrm{~g}$. Total protein content was determined by the Lowry method. Amino acids and amino sugars were quantified on an amino acid analyser (Beckman model 120C). Phosphorus was assayed in hydrolysed antigens using the Gemeni inorganic 
phosphorus UV (Electro-nucleonics, Fairfield, NJ, USA). This system was based on the method described by Daly \& Ertingshausen (1972) as modified by Amador \& Urban (1972). Nucleic acids were quantified by determining the $A_{254}^{1} \mathrm{~cm}$ of an aqueous antigen solution and comparing with serial dilutions of yeast nucleic acids (K and $\mathrm{K}$ Laboratories, Jamaica, NY, USA).

Pentoses, hexoses, hexosamines and sugar alcohols were determined as their alditol acetate derivatives (Clamp et al., 1971; Fraser \& Mallette, 1973). The hydrolysates were dissolved in water $(1 \mathrm{ml})$ and $\mathrm{NaBH}_{4}(5 \mathrm{mg})$ was added. Reduction proceeded overnight and the reaction mixture was made slightly acidic with acetic acid and evaporated in vacuo. Methanolic acetic acid $(9: 1, \mathrm{v} / \mathrm{v})(1 \mathrm{ml})$ was added and evaporated followed by dry methanol to remove the boric acid. The alditols were acetylated with pyridine and acetic anhydride at $120^{\circ} \mathrm{C}$ for 20 min. The acetylation mixture was evaporated to dryness and dissolved in acetone. The alditol acetate derivatives were analysed by a gas-liquid chromatograph (Perkin-Elmer model 990$)$ fitted with glass columns $(0.9 \mathrm{~m} \times 2 \mathrm{~mm}$ i.d. and $1.8 \mathrm{~m} \times 2 \mathrm{~mm}$ i.d.) of $3 \%$ SP-2340 on 100/120 Supelcoport (Supelco). Temperature was programmed from 175 to $225^{\circ} \mathrm{C}$ at $2{ }^{\circ} \mathrm{C} \mathrm{min}^{-1}$. Carboxyl groups of uronic acids were reduced by the method of Taylor \& Conrad (1972). Acid hydrolysates from the carboxyl-reduced carbohydrates were then analysed as their alditol acetate derivatives (Kozel \& Gotschlich, 1982).

Fatty acids were identified as their methyl esters (Metcalfe \& Schmitz, 1961). Ester-linked fatty acids were first released by saponification with $10 \%(\mathrm{w} / \mathrm{v})$ potassium hydroxide in methanol and amide-linked fatty acids were released by hydrolysis with $4 \mathrm{M}-\mathrm{HCl}$ (Lambert \& Moss, 1983). After esterification with boron trifluoride/methanol, the methyl esters were analysed by gas-liquid chromatography using a glass column $(1.8 \mathrm{~m} \times 2 \mathrm{~mm}$ i.d. $)$ containing $3 \%$ SP-2100 DOH on 100/120 Supelcoport.

\section{RESULTS}

\section{Determination of isoelectric point}

The initial purifications of the EXP from $S$. aureus strain Smith diffuse involved TCA extraction and also Cetavlon precipitation from culture supernatants as described by McDonald \& Karakawa (1970). The precipitates were further purified by treatment with DNAase, RNAase, and trypsin followed by DEAE-chromatography (Pharmacia) with ammonium carbonate elution. A final purification involved application of the precipitate to a Sephadex G-150 column (Pharmacia) and elution with $1.0 \mathrm{M}-\mathrm{NaCl}, 0.02 \% \mathrm{NaN}_{3}, \mathrm{pH} 7 \cdot 4$.

Since the initial studies of this antigen preparation with crossed immunoelectrophoresis indicated that several components were present (Fig. 1), isoelectric focusing studies were done between $\mathrm{pH} 7.8$ amd $\mathrm{pH} 2.48$. Immunologically active components with precipitins to Smith diffuse antiserum were found in three separate bands (Fig. 2). Precipitins were found in fractions from both extremes of the $\mathrm{pH}$ range (7.48 and 2.48). Neither of the precipitins from the $\mathrm{pH}$ extremes was reactive with Smith diffuse antiserum absorbed with either Smith compact or Smith diffuse micro-organisms (Fig. 2). In contrast, two separate precipitins were localized to a narrow $\mathrm{pH}$ band extending from $\mathrm{pH} 3.52$ to 3.96 . These precipitins differed in their reactivity to Smith diffuse antiserum absorbed with Smith compact organisms but neither was present against Smith diffuse antiserum absorbed with Smith diffuse organisms (Fig. 2).

Isoelectric focusing between $\mathrm{pH} 2.00$ and 5.82 was also performed on the purified cell wall teichoic acid previously prepared from the Smith compact strain. The teichoic acid was

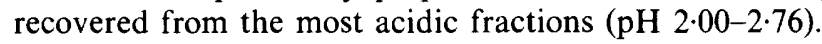

\section{Immunological analysis of EXP preparation}

The method of preparation of the EXP from the $S$. aureus Smith diffuse strain evolved from the isoelectric focusing findings. Acidified and digested culture supernatant was applied to a cation-exchange column using a dilute $\mathrm{pH} 2.60$ buffer. The column was equilibrated at $\mathrm{pH} 2.60$ and then EXP was eluted with buffer at pH 3.6 (see Methods). Similarly, immunologically active fractions from the Sepharose $6 \mathrm{~B}$ column were detected in the void volume as determined with Blue Dextran (Pharmacia). The approximate yield of EXP from 41 culture supernatant was $10 \mathrm{mg}$.

Crossed immunoelectrophoresis of the final EXP preparation showed two long precipitin lines when Smith diffuse antiserum was employed in the second phase (Fig. $3 a$ ). Substitution of Smith diffuse antiserum absorbed with Smith compact organisms in the second phase resulted in almost complete removal of one precipitin line (Fig. $3 b$ ). Both precipitin lines were removed 


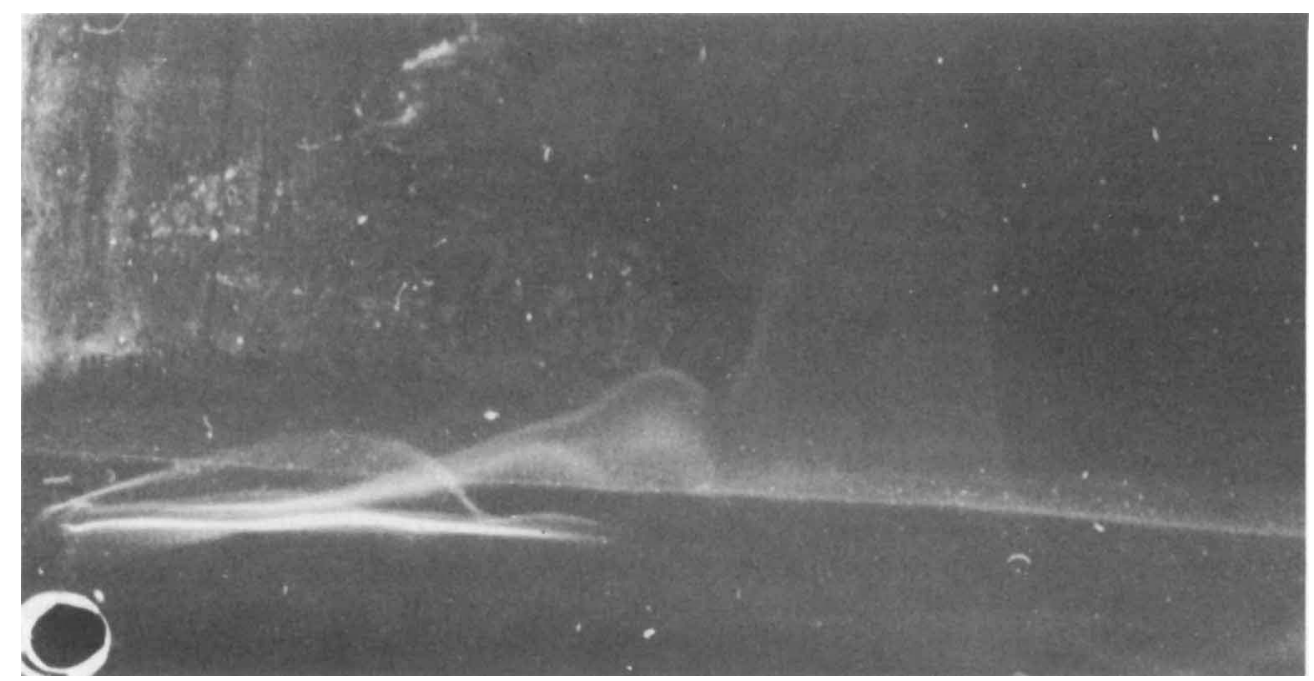

Fig. 1. Crossed immunoelectrophoresis of the initial Smith diffuse EXP preparation $\left(1 \mathrm{mg} \mathrm{ml}^{-1}\right)$. Second-dimension electrophoresis was done into a gel containing rabbit anti-S. aureus Smith diffuse serum.
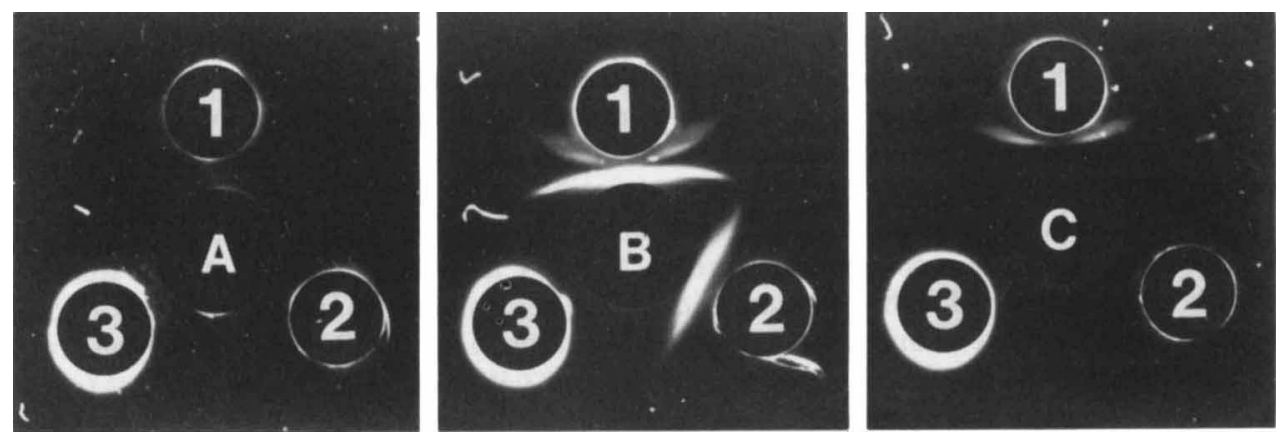

Fig. 2. Isoelectric focusing of the initial Smith diffuse EXP preparation between $\mathrm{pH} 7.48$ and $\mathrm{pH} 2.48$ revealed antigenic components localized to (A) $\mathrm{pH}>7.48$, (B) $\mathrm{pH} 3.6$, and (C) $\mathrm{pH}<2.48$. The immunodiffusion reaction of each component between rabbit anti-Smith diffuse serum (1), anti-Smith diffuse serum absorbed with the variant, Smith compact (2), and anti-Smith diffuse absorbed with Smith diffuse (3) is shown.

when the second phase contained Smith diffuse antiserum absorbed with Smith diffuse organisms. This precipitin pattern was unchanged even when individual fractions throughout the Sepharose 6B peak were analysed separately. Tandem immunoelectrophoresis with Smith diffuse antiserum showed that EXP was not teichoic acid (Fig. 4).

\section{Chemical analysis of staphylococcal antigens}

Chemical analysis for amino acids, phosphate, sugar alcohols and amino sugars was done to estimate the contamination of EXP with peptidoglycan or teichoic acid. The results for teichoic acid and peptidoglycan were consistent with published values for these structures (Peterson $e t$ al., 1978; Verbrugh et al., 1981). Phosphate was insignificant in the peptidoglycan while it constituted $1.2 \mu \mathrm{mol}(\mathrm{mg} \text { teichoic acid })^{-1}$ and $0.5 \mu \mathrm{mol}(\mathrm{mg} \mathrm{EXP})^{-1}$. Muramic acid was not detected in the teichoic acid or EXP. Ribitol was not found in either the peptidoglycan or the EXP. The total protein content calculated from amino acid analysis of the Smith diffuse EXP 

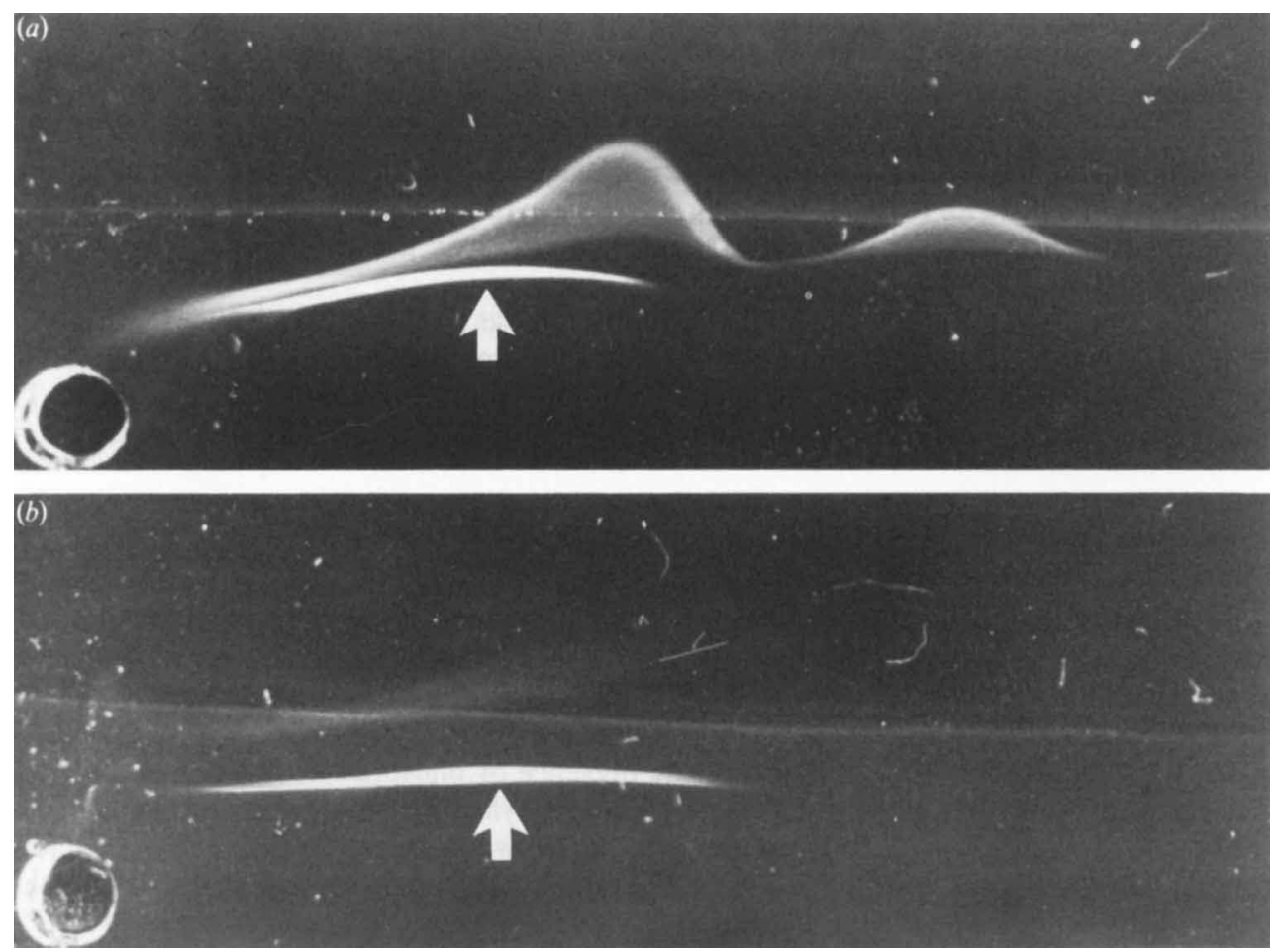

Fig. 3. Crossed immunoelectrophoresis of the final Smith diffuse EXP preparation $\left(1 \mathrm{mg} \mathrm{ml}^{-1}\right)$. Second-dimension electrophoresis was done $(a)$ into a gel containing rabbit anti-Smith diffuse serum, and $(b)$ into a gel containing rabbit anti-Smith diffuse serum absorbed with the variant, Smith compact. In $(a)$, two separate long precipitin arcs are present; the major precipitin is arrowed. In $(b)$, the major precipitin arc (arrow) persists while the second component essentially disappears.

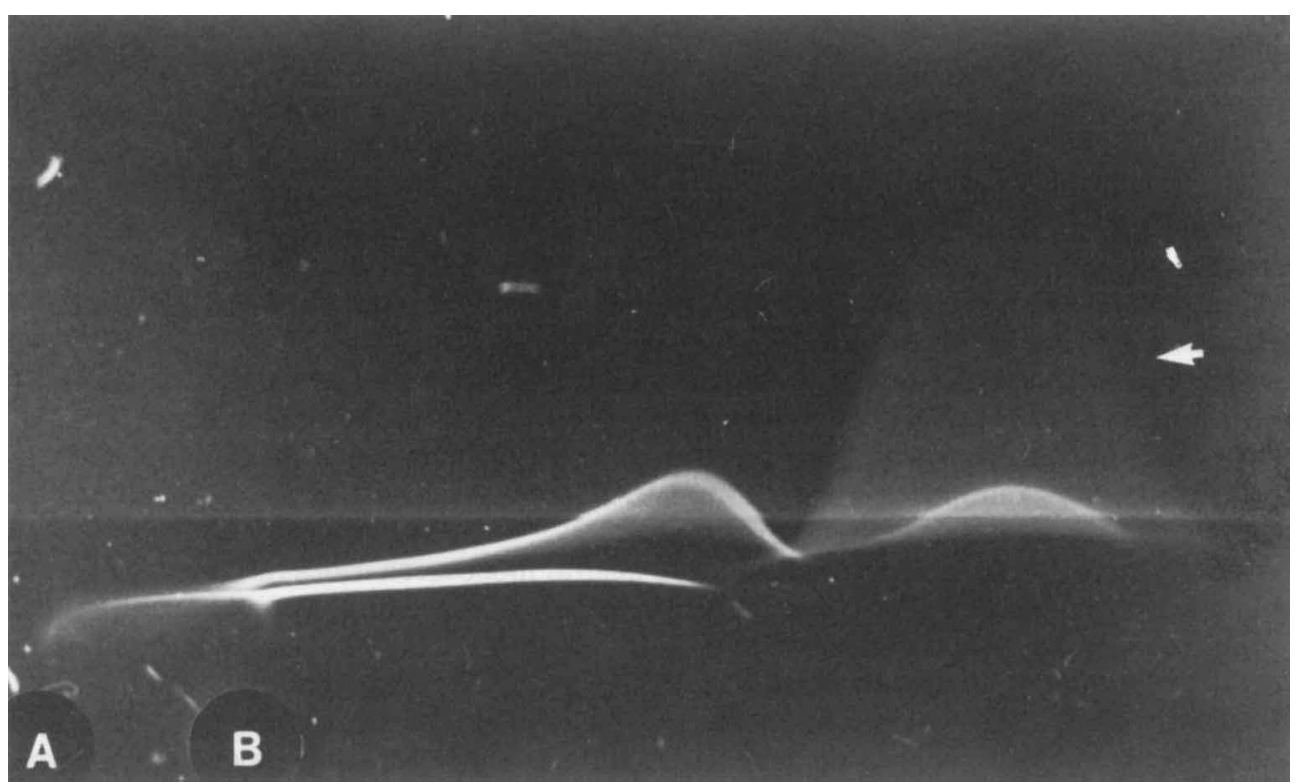

Fig. 4. Tandem immunoelectrophoresis of the Smith diffuse EXP preparation ( $\left.1 \mathrm{mg} \mathrm{ml}^{-1}\right)$ (well A) with Smith compact cell wall teichoic acid $\left(0.12 \mathrm{mg} \mathrm{m}^{-1}\right)$ (well B). Teichoic acid (arrowhead) was different from the EXP. 
was $6.2 \%$ or $<2 \%$ by the Lowry method. Analysis of the EXP for fatty acids failed to reveal that a significant quantity was present. The content of nucleic acids was also insignificant $(<1 \%)$.

Analysis for neutral sugars after hydrolysis of the EXP at $120^{\circ} \mathrm{C}$ for $2 \mathrm{~h}$ with $2 \mathrm{M}$ trifluoroacetic acid revealed primarily glucose and mannose (molar proportion 1:0.90) with trace amounts of galactose and a pentose or deoxy sugar with a retention time similar to xylose (molar proportion 0.12 for each). After more extensive hydrolysis at $100{ }^{\circ} \mathrm{C}$ for $3 \mathrm{~h}$ with $4 \mathrm{M}-\mathrm{HCl}$, glucose, mannose and galactose were again the principal neutral sugars present (molar proportion $1 \cdot 0: 0 \cdot 23: 0 \cdot 13$ ).

After carboxyl reduction of the EXP, the preparation was hydrolysed with $3 \mathrm{M}-\mathrm{HCl}$ for $16 \mathrm{~h}$ at $100^{\circ} \mathrm{C}$. Analysis of alditol acetate derivatives of this reduced preparation was then compared to the non-reduced EXP. The reduced EXP showed a fivefold increase in glucosamine. This finding suggests that the EXP contained major quantities of 2-amino-2-deoxyglucuronic acid.

\section{DISCUSSION}

EXP isolated from $S$. aureus strain Smith diffuse essentially as outlined by McDonald \& Karakawa (1970) contained significant amounts of teichoic acid. Isoelectric focusing, however, indicated a way to separate the two polysaccharides. The isoelectric point of 3.6 for the exopolysaccharide agreed closely with the value of 3.3 found by Haskell \& Hanessian (1963, 1964), whereas teichoic acid was considerably more acid with a value of $2 \cdot 0$. A similar value was reported by Haukenes (1962) and refiects the presence of phosphodiester linkages.

Teichoic acid may be difficult to exclude from staphylococcal EXP preparations (Brock \& Reiter, 1976). Liau et al. (1974) reported that EXP was separated from teichoic acid by molecular-sieve chromatography in $1 \mathrm{M}-\mathrm{NaCl}$, which prevented aggregation of the teichoic acid, while Murthy et al. (1983) found that chromatography of the $S$. aureus strain M EXP on QAE-Sephadex A-50 (Pharmacia) was adequate for the removal of teichoic acid. Fournier $e t$ al. (1984) reported purification of $S$. aureus type 8 EXP by chromatography on DEAE-Sephacel followed by Sephacryl S-300. Our initial separation of EXP from teichoic acid employed a cation-exchange column at $\mathrm{pH} 2.60$ to ensure binding of the EXP while excluding the teichoic acid. Although Haskell \& Hanessian (1963) reported that salt solutions of EXP were not absorbed on sulphonic acid exchange resins, in our hands EXP bound readily with acid buffers, perhaps indicating the presence of basic groups.

Crossed immunoelectrophoresis of the EXP preparation revealed two distinct precipitin lines (Fig. 3), one of which was not removed by absorbing Smith diffuse hyperimmune sera with the nonencapsulated variant, Smith compact. The two components could not be separated by cation-exchange or molecular-sieve chromatography. Ekstedt \& Bernhard (1973) reported gelimmunodiffusion studies on EXP prepared from several $S$. aureus strains including Smith diffuse. They found that two precipitin lines formed in the interaction with homologous Smith diffuse antisera. Morse (1962) also noted double precipitin formation of his preparation on gel-immunodiffusion, especially at higher antigen concentrations $\left(1 \mathrm{mg} \mathrm{ml}^{-1}\right)$. He further speculated that this pattern may have been a result of minor structural alterations of the polysaccharide polymers. These studies are difficult to compare because of differences in isolation methods and our use of the more sensitive crossed immunoelectrophoresis. Caputy \& Costerton (1984) examined a Smith diffuse EXP preparation with crossed immunoelectrophoresis and reported five separate precipitins.

Ribitol was not detectable in the EXP. The neutral monosaccharides released by hydrolysis were glucose, mannose, and galactose. 2-Amino-2-deoxyglucuronic acid was present, probably $N$-acylated with acetyl and amino acids. With the exception of neutral monosaccharides, these results are similar to studies by Haskell \& Hanessian $(1963,1964)$ and Hanessian \& Haskell (1964). Although total protein content was $<2 \%$ by the Lowry method, analysis on an amino acid analyser revealed a slightly higher protein content. This estimation may not reflect protein contamination but may include structural components such as amino sugars. Detailed chemical and structural analysis of the Smith diffuse EXP with nuclear magnetic resonance and other nondegradative techniques are in progress. 
This method of purification offers an alternative means of separating the Smith diffuse EXP from teichoic acid constituents of staphylococci. Its isolation aids in establishing data regarding its production by clinical strains of $S$. aureus and in furthering serological investigations concerning its immunogenicity in $S$. aureus infections.

We thank Marcia West for her technical assistance. This investigation was supported by Public Health Service grant 1R23AI18654 from the National Institutes of Health.

\section{REFERENCES}

Amador, E. \& Urban, J. (1972). Simplified serum phosphorus analyses by continuous-flow ultraviolet spectrophotometry. Clinical Chemistry 18, 601-604.

BROCK, J. H. \& ReITER, B. (1976). Chemical and biological properties of extracellular slime produced by Staphylococcus aureus grown in high-carbohydrate, high-salt medium. Infection and Immunity 13, 653-660.

Caputy, G. G. \& Costerton, J. W. (1984). Immunological examination of the glycocalyces of the Staphylococcus aureus strain Wiley and Smith. Current Microbiology 11, 297-302.

Clamp, J. R., Bhatti, T. \& Chambers, R. E. (1971). The determination of carbohydrate in biological materials by gas-liquid chromatography. In Methods of Biochemical Analysis, vol. 1, pp. 229-344. Edited by D. Glick. New York: Wiley.

Daly, J. A. \& Ertingshausen, G. (1972). Direct method for determining inorganic phosphate in serum with the CentrifiChem'. Clinical Chemistry 18 , 262-265.

EkstedT, R. D. \& Bernhard, J. M. (1973). Preparation and characterization of a slime layer material produced by Staphylococcus aureus (36964). Proceedings of the Society of Experimental Biology and Medicine 142, 86-91.

Fournier, J. M., VANN, W. F. \& Karakawa, W. W. (1984). Purification and characterization of Staphylococcus aureus type 8 capsular polysaccharide. Infection and Immunity 45, 87-93.

Frazer, B. A. \& Mallette, M. F. (1973). An improved isolation method and new composition data for Forssman hapten from sheep erythrocytes. Immunochemistry 10, 745-753.

HANESSIAN, S. \& HASKell, T. H. (1964). Structural studies on staphylococcal polysaccharide antigen. Journal of Biological Chemistry 239, 2758-2764.

Haskell, T. H. \& Hanessian, S. (1963). 2-Amino-2deoxy-D-glucuronic acid, the main constituent of SPA (staphylococcal polysaccharide antigen). Nature, London 199, 1075-1076.

Haskell, T. H. \& Hanessian, S. (1964). The purification and characterization of a new active immunizing polysaccharide prepared from Staphylococcus aureus. Biochimica et biophysica acta 83, 35-41.

HaUkenes, G. (1962). Immunochemical studies on polysaccharide A of Staphylococcus aureus. 7. On the chemical basis of the serological reactivity and the nature of the extraction process. Acta pathologica et microbiologica scandinavica 55, 463-474.

Hunt, G. A. \& Moses, A. J. (1958). Acute infection of mice with Smith strain of Staphylococcus aureus. Science 128, 1574-1575.
KoENIG, M. G. (1962). Factors relating to the virulence of staphylococci. I. Comparative studies on two colonial variants. Yale Journal of Biology and Medicine 34, 537-559.

Kozel, T. R. \& Gotschlich, E. C. (1982). The capsule of Cryptococcus neoformans passively inhibits phagocytosis of the yeast by macrophages. Journal of Immunology 129, 1675-1680.

LAMbert, M. A. \& Moss, C. W. (1983). Comparison of the effects of acid and base hydrolyses on hydroxy and cyclopropane fatty acids in bacteria. Journal of Clinical Microbiology 18, 1370-1377.

LiaU, D., Melly, M. A. \& Hash, J. H. (1974). Surface polysaccharide from Staphylococcus aureus $\mathrm{M}$ that contains taurine, D-aminogalacturonic acid, and Dfucosamine. Journal of Bacteriology 119, 913-922.

MCDonald, H. C. \& Karakawa, W. W. (1970). Immunochemical analysis of a uronic acid polymer of Staphylococcus epidermidis, strain 53. Journal of Immunology 105, 389-395.

Metcalfe, L. D. \& Schmitz, A. A. (1961). The rapid preparation of fatty acid esters for gas chromatographic analysis. Analytical Chemistry 33, 363-364.

MORSE, S. I. (1962). Isolation of a surface antigen of Staphylococcus aureus. Journal of Experimental Medicine 115, 295-311.

Murthy, S. V. K. N., Melly, M. A., Harris, T. M., Hellerqvist, C. G. \& HASH, J. H. (1983). The repeating sequence of the capsular polysaccharide of Staphylococcus aureus M. Carbohydrate Research 117, 113-123.

OEDING, P. (1957). Agglutinability of pyogenic staphylococci at various conditions. Acta pathologica et microbiologica scandinavica 41, 310-324.

Peterson, P. K., Wilkinson, B. J., Kim, Y., SChMelING, D., Douglas, S. D., QuiE, P. G. \& Verhoef, J. (1978). The key role of peptidoglycan in opsonization of Staphylococcus aureus. Journal of Clinical Investigation 61, 597-609.

RighetTI, P. G. \& DRYSDALE, J. W. (1979). Isoelectric focusing. In Laboratory Techniques in Biochemistry and Molecular Biology, pp. 1-323. Edited by T. S. Work \& E.Work. New York: North-Holland Publishing Co.

SMIth, J. M. \& Dubos, R. J. (1956). The behavior of virulent and avirulent staphylococci in the tissues of normal mice. Journal of Experimental Medicine 103, 87-107.

TAYLOR, R. L. \& CONRAD, H. E. (1972). Stoichiometric depolymerization of polyuronides and glycosaminoglycuronans to monosaccharides following reduction of their carbodiimide-activated carboxyl groups. Biochemistry 11, 1383-1388. 
Verbrugh, H. A., Peters, R., Rozenberg-Arska, M., Peterson, P. K. \& Verhoef, J. (1981). Antibodies to cell wall peptidoglycan of Staphylococcus aureus in patients with serious staphylococcal infections. Journal of Infectious Diseases 144, 1-9.
West, T. E., West, M. E. \& Mylotte, J. M. (1985). Antiserum agar method for identification of Smith type exopolysaccharides in clinical isolates of Staphylococcus aureus. Journal of Clinical Microbiology 21, 490-492. 